\title{
Modifications to swede (Brassica napus L.) anterior to the terminal ileum of pigs: some implications for the analysis of dietary fibre
}

\author{
By P. MILLARD* AND A. CHESSON \\ Rowett Research Institute, Bucksburn, Aberdeen AB2 9SB
}

(Received 11 August 1983 - Accepted 22 June 1984)

\begin{abstract}
1. The degradation of a swede (Brassica napus L., cv. Danestone) diet anterior to the terminal ileum was studied in two pigs fitted with $T$-shaped cannulas $150 \mathrm{~mm}$ before the ileo-caecal junction. Digestibility was calculated with reference to chromic oxide and polyethylene glycol.

2. In addition to the total loss of free glucose and fructose, there were substantial modifications to cell-wall material recovered in digesta. These included the apparent loss of 46-50\% of uronic acid residues, 72-78\% of phenolic material and $10-24 \%$ of cellulose initially present in the feed, and a partial solubilization of some hemicellulose components.

3. Since 'fibre' recovered at the terminal ileum differed in a number of important respects from ingested fibre, a number of methods for the analysis of dietary fibre were examined to establish (1) the extent to which analysis of feed represented material recovered at the terminal ileum and (2) whether such methods could be applied directly to digesta samples. Results were compared with a complete analysis of water-soluble $(620 \mathrm{~g} / \mathrm{kg}$ dry matter $)$ and water-insoluble $(380 \mathrm{~g} / \mathrm{kg}$ dry matter) fractions of feed.

4. Chemical fractionation techniques gave more reliable quantitative estimates of fibre than in vitro enzymic digestion methods which overestimated fibre. Acid- and neutral-detergent methods both gave too low an estimate of fibre. As none of the methods could allow for the loss of components (particularly pectic polysaccharides) found by sampling at the terminal ileum, none gave an accurate qualitative or quantitative representation of fibre at this point in the gut.

5. It is suggested that, as vegetable fibre recovered at the terminal ileum has already undergone partial hydrolysis, a more dynamic model of dietary fibre, in which the action of gut micro-organisms is considered, may be required to establish possible physiological roles of fibre or fibre components in the digestive tract. Recovery of digesta from sites of interest may be the only way of reliably estimating fibre or specific fibre components at different levels of the gut. This approach to dietary fibre may be impractical when applied directly to humans but the digestive tract of the pig may be a suitable alternative model.
\end{abstract}

It is proposed that dietary fibre has an important role in the avoidance of a number of human diseases associated with a highly refined diet (Burkitt \& Trowell, 1975). There is, however, conflicting epidemiological evidence for the role of dietary fibre in disease prevention, and there has been little success in identifying those fibre components responsible for the effects noted in clinical trials (Cummings, 1981). A major problem in such studies has been the lack of a consensus on what constitutes fibre in food.

A common definition of dietary fibre, first used by Trowell et al. (1976), is the plant polysaccharides (including storage polysaccharides and mucilages) and lignin which are resistant to hydrolysis by the digestive enzymes of man. Others have considered any component of the total diet to be included if it is not digested and absorbed in the small intestine. Indigestible cell-wall-bound proteins and minerals (Spiller et al. 1976; Theander \& Aman, 1979a) have therefore been included in this wider definition.

Methods developed to measure dietary fibre may be considered as falling into one of two categories: (1) sequential chemical extraction; (2) in vitro enzymic digestions.

The chemical extractions used range from simple gravimetric acid (ADF)- or neutral (NDF)-detergent-fibre methods (Van Soest, 1963; Van Soest \& Wine, 1967) to complex fractionation schemes based on an understanding of the structure and composition of plant cell walls. These methods provide a measure of the carbohydrate and lignin content of food,

* Present address: Macaulay Institute for Soil Research, Craigiebuckler, Aberdeen AB9 2QT. 
the fractions of which may be summed to give a value for dietary fibre (Southgate, 1976; Selvendran et al. 1979; Theander \& Åman, 1979 b). In contrast, the enzymic methods require an understanding of digestive physiology rather than plant-cell-wall structure and attempt to mimic the endogenous secretions of the host animal (Hellendoorn et al. 1975; Schweizer \& Würsch, 1979).

Dietary fibre may be modified substantially during passage through the gut by the non-enzymic effects of digestive secretions and, in particular, as a result of microbial activity. Although fermentation of plant polysaccharides in the hind gut is well recognized, analysis of samples from ileostomy patients has suggested that changes in the composition of fibre may occur before entry into the large intestine (Sandberg, 1982; Holloway et al. 1983). Such modifications need to be considered when assessing the possible physiological role of fibre or specific fibre components in the upper digestive tract.

The present study was undertaken: (1) to measure the extent of digestion of dietary fibre components in the small intestine of the pig given a vegetable diet with a high soluble fibre content; (2) to compare several methods of dietary fibre analysis in both feed and ileal digesta, and to determine the extent to which methods developed for the analysis of feeds could be applied directly to digesta samples; (3) to consider the suitability of the pig as a model for human digestion.

\section{MATERIALS AND METHODS}

\section{Animals and housing}

The experiments were carried out on two Large White $\times$ (Landrace $\times$ Large White) female pigs weighing $165 \mathrm{~kg}$ (pig A) and $160 \mathrm{~kg}$ (pig B), each fitted with a T-shaped cannula $150 \mathrm{~mm}$ before the ileo-caecal junction. Such cannulation does not appear to affect the efficiency of digestion anterior to the ileo-caecal junction, in spite of some disruption of the digesta flow (Wenham \& Wyburn, 1980). No formal proof of digestive efficiency equivalent to that found in the intact animal can, however, be readily obtained. The animals were housed individually in smooth-walled pens with a floor area $2.3 \times 2.0 \mathrm{~m}$. The ambient temperature was maintained at about $20^{\circ}$ and water was freely available from drinking bowls. Bedding material was not provided during periods of experimental work.

\section{Diets}

Swedes (Brassica napus L., cv. Danestone) were prepared by maceration in a Wolfking mincer. The experimental diet consisted of macerated swede supplemented with minerals, trace elements and vitamins $\left(\mathrm{g} / \mathrm{kg}\right.$ dry matter; 13.2 dicalcium phosphate, 0.3 vitamin $\mathrm{B}_{12}$ supplement, 2.5 vitamin-trace element supplement). In addition, $5 \mathrm{~g}$ chromic oxide and $10 \mathrm{~g}$ polyethylene glycol 4000 (PEG) were added per kg dry matter, as insoluble and soluble markers respectively. Feeds were thoroughly mixed and individual portions weighed into polyethylene bags and stored at $4^{\circ}$. The pigs were given $2.5 \mathrm{~kg}$ feed four times daily at $08.00,11.00,14.00$ and 17.00 hours. A gradual loss of appetite occurred after feeding this diet for more than $5 \mathrm{~d}$ so between periods of digesta collection, animals were given a feed comprising $(\mathrm{g} / \mathrm{kg}) 500$ swede and 500 cereal feed (based on barley, weatings and extracted soya-bean meal) on a dry matter basis.

\section{Collection of digesta}

Animals were given the experiment diet for $3 \mathrm{~d}$ before digesta samples were collected. A PVC tube $(300 \times 50 \mathrm{~mm})$ was attached to each cannula from 09.30 to 16.30 hours on the day of collection, and emptied as necessary to collect all forthcoming digesta (2-5 litres). The length of digesta collection was sufficient to minimize any sampling errors due to a circadian rhythm of digestibility (Livingstone et al. 1980). Feed samples were also taken 
on the day of collection, and both digesta and feed samples were freeze-dried, milled and stored at $-20^{\circ}$.

\section{Chemical analysis}

Samples were separated into water soluble or insoluble fractions by suspending $5.0 \mathrm{~g}$ of material in $80 \mathrm{ml}$ water, stirring for $30 \mathrm{~min}$ at room temperature, then centrifuging at $17000 \mathrm{~g}$ for $30 \mathrm{~min}$. The supernatant fraction was retained and the pellet re-extracted twice as described. The pellets and combined supernatants were freeze-dried and the weight of each fraction measured.

Monomeric glucose, fructose and mannose levels in soluble samples were determined by the u.v. enzymic methods (Boehringer Mannheim) using hexokinase ( $E C$ 2.7.1.1), $\beta$-fructofuranosidase (EC 3.2.1.26) and phosphomannose isomerase ( $E C$ 5.3.1.8) respectively. For the determinations of other neutral sugars, soluble samples $(60 \mathrm{mg})$ were hydrolysed with $3 \mathrm{ml} 0.5 \mathrm{M}$-sulphuric acid at $100^{\circ}$ for $3 \mathrm{~h}$ and neutralized with $15 \mathrm{M}$-ammonia

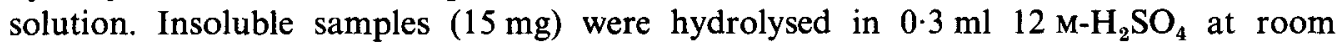
temperature for $1 \mathrm{~h}$, diluted with water to give $1.0 \mathrm{M}-\mathrm{H}_{2} \mathrm{SO}_{4}$ then heated to $100^{\circ}$ for $5 \mathrm{~h}$ before neutralization as described previously. Monosaccharides released from samples by acid-hydrolysis were determined as their alditol acetates, prepared by the method of Blakeney et al. (1983) and separated by gas-liquid chromatography (GLC) using the method of Bacon \& Gordon (1980). The method of Kintner \& Van Baren (1982) was used for the determination of uronic acids in the acid-hydrolysates. Methylation analysis of polysaccharides used the preparative methods of Lomax et al. (1983) and the separation and identification procedures of Lomax \& Conchie (1982).

Volatile fatty acids (VFA) were analysed by the GLC method of Supelco Inc. (1975) for acetic, propionic and butyric acids. Lactic acid was determined by the microdiffusion technique described by Conway (1957). An estimate of the total phenolic content of samples was made using the acetyl bromide method described by Morrison (1972), against calibrations prepared with known amounts of ferulic acid. The cellulose content of water-insoluble fractions was determined by the method of Updegraff (1969). Ash was estimated by the method of the Association of Official Agricultural Chemists (1965), insoluble nitrogen by a microKjeldahl method, and soluble protein by the technique of Read \& Northcote (1981) with bovine serum albumin as a standard.

Before analysis of PEG in total feed or digesta samples, $1.5 \mathrm{~g}$ was hydrated with $10 \mathrm{ml}$ water, shaken at $4^{\circ}$ for $16 \mathrm{~h}$, a further $10 \mathrm{ml}$ water added and the samples centrifuged at $17000 \mathrm{~g}$ for $30 \mathrm{~min}$. The pellet was washed twice with $20 \mathrm{ml}$ water and a portion of the combined supernatant fractions used for the determination of PEG by the technique of Malawar \& Powell (1967). Analysis of $\mathrm{Cr}_{2} \mathrm{O}_{3}$ in total feed and digesta samples was by the method of Hesford \& Buhrer (1978).

\section{Dietary fibre preparations}

Feed and digesta samples were fractionated by various methods used to determine dietary fibre. Methods used were the enzymic digestions of Schweizer \& Würsch (1979) and Dovell \& Harris (1982); extractions of Theander \& Åman (1979b) and Chen \& Anderson (1981) and ADF and NDF methods of Van Soest (1963) and Van Soest \& Wine (1967). All soluble and insoluble fibre-fractions produced were freeze-dried and the individual components analysed by the methods described here, rather than those used by the various authors. 
Table 2. The apparent loss of water-insoluble components from a swede diet recovered from the terminal ileum calculated using cellulose as an internal marker

(Values are means with their standard errors for six replicate experiments for pig A and three for pig B)

\begin{tabular}{|c|c|c|c|c|}
\hline \multirow[b]{3}{*}{ Component } & \multicolumn{4}{|c|}{ Loss of feed dry matter $(\%)$} \\
\hline & \multicolumn{2}{|c|}{ Pig A } & \multicolumn{2}{|c|}{ Pig B } \\
\hline & Mean & SE & Mean & $\mathbf{S E}$ \\
\hline Rhamnose & $0 \cdot 12$ & 0.04 & $0 \cdot 13$ & 0.03 \\
\hline Fucose & 0.01 & 0.01 & 0 & \\
\hline Arabinose & 0.33 & 0.07 & 0.22 & 0.06 \\
\hline Xylose & $0 \cdot 22$ & 0.03 & $-0 \cdot 15$ & 0.04 \\
\hline Mannose & 0.12 & 0.12 & -0.12 & 0.04 \\
\hline Galactose & 0.20 & 0.08 & $0 \cdot 15$ & 0.09 \\
\hline Cellulose & 0 & & 0 & \\
\hline Uronic acids & 5.97 & 0.54 & 4.79 & 1.60 \\
\hline Phenolics & -0.03 & 0.16 & -0.45 & 0.06 \\
\hline
\end{tabular}

Table 3. $(I \rightarrow 4)$-Linked glucose present in the feed and recovered from the digesta of pigs

(Values are expressed as $\mathrm{g} / \mathrm{kg}$ feed dry matter and are means with their standard error for six replicate experiments in the case of pig A and three replicates in the case of pig B)

\begin{tabular}{lccccc}
\hline & \multicolumn{5}{c}{ g/kg Feed dry matter } \\
\cline { 2 - 3 } \cline { 5 - 6 } & \multicolumn{2}{c}{ Pig A } & & \multicolumn{2}{c}{ Pig B } \\
\cline { 2 - 3 } \cline { 5 - 6 } & Mean & SE & & Mean & SE \\
\hline Glucose in feed & 112.7 & 4.5 & & 105.0 & 10.3 \\
Glucose in digesta & 85.8 & 7.0 & & 80.7 & 10.0 \\
Loss & 26.9 & 3.3 & & 24.3 & 17.7 \\
\hline
\end{tabular}

\section{RESULTS}

\section{Modification of a swede diet by passage through the small intestine}

A dual-phase marker system was used throughout and the ratio, $\mathrm{Cr}_{2} \mathrm{O}_{3}$ : $\mathrm{PEG}$ in feed and digesta samples compared. The mean (with $\mathrm{SE}$ ) values for feed and digesta respectively were 1.81 (SE 0.09) and 1.94 (SE 0.20) for pig A and 1.97 (SE 0.04) and 2.52 (SE 0.18) for pig B. When calculating the quantity of each soluble fibre component an arithmetic correction was made to allow for discrepancy between the marker ratios in the appropriate feed and digesta samples. The fractions of the major swede constituents recovered from the terminal ileum are shown in Table 1 together with the original composition of the feed.

Two distinct modifications to the swede diet were detected in digesta recovered from the terminal ileum. Firstly, there was a loss of virtually all soluble glucose, fructose and phenolic material, and an approximately $50 \%$ loss of uronic acids, galactose and arabinose. In addition, there was a partial loss from the insoluble fraction of the feed of each of the neutral sugars, uronic acids and phenolic material, suggesting that some solubilization of cell-wall material had taken place.

The levels of cellulose found in the digesta were also lower than those in the diets for both animals (Table 1). To confirm that this loss was not an artefact due to possible errors associated with the insoluble-phase marker used (for example $\mathrm{Cr}_{2} \mathrm{O}_{3}$ not passing at the same 
Table 4. Organic acids recovered in digesta from the terminal ileum

(Values are expressed as $\mathrm{g} / \mathrm{kg}$ digesta dry matter and are means with their standard errors for six replicate samples for pig $\mathbf{A}$ and three for pig B)

\begin{tabular}{|c|c|c|c|c|}
\hline \multirow[b]{3}{*}{ Acid } & \multicolumn{4}{|c|}{$\mathrm{g} / \mathrm{kg}$ Digesta dry matter } \\
\hline & \multicolumn{2}{|c|}{ Pig A } & \multicolumn{2}{|c|}{ Pig B } \\
\hline & Mean & $\mathrm{SE}$ & Mean & SE \\
\hline Acetic & $35 \cdot 1$ & $6 \cdot 4$ & $11 \cdot 7$ & 0.9 \\
\hline Propionic & 17.3 & $5 \cdot 4$ & 8.0 & $0 \cdot 3$ \\
\hline Butyric & $7 \cdot 6$ & $0 \cdot 6$ & 0.7 & $0 \cdot 2$ \\
\hline Lactic & $16 \cdot 4$ & $2 \cdot 8$ & $27 \cdot 6$ & $2 \cdot 4$ \\
\hline
\end{tabular}

rate as the insoluble phase of digesta, or not being closely associated with that phase) the values for the water-insoluble components were recalculated using cellulose as an internal marker, thereby assuming no loss (Table 2). This reduced the apparent losses of phenolic material, uronic acids and galactose, while xylose was recovered from the digesta of both pigs in amounts greater than those consumed. This strongly suggested that an absolute loss of cellulose had occurred. The phenomenon was further studied by methylation analysis of insoluble polysaccharides of feed and digesta to measure specifically $(1 \rightarrow 4)$-linked glucose, a more accurate determination of cellulose than the colorimetric assay used. Again, results indicated an absolute loss of cellulose anterior to the terminal ileum (Table 3).

Analysis of organic acids recovered from digesta

VFA and lactic acid were identified in the digesta samples recovered from both pigs (Table 4). However, measurements were made on freeze-dried material. Although the $\mathrm{pH}$ of digesta was near neutrality, subsequent checks on the effect of freeze-drying on VFA recovery indicated that the values shown in Table 4 are underestimated by approximately $10 \%$ overall.

\section{Analysis of dietary fibre}

Results shown in Table 1 indicated that when ash and residual free sugars were excluded a loss of approximately $40 \%$ of the dry matter from the swede diets occurred before digesta passed into the hind gut.

\section{Comparative analysis of a feed sample}

A single feed and corresponding digesta sample from pig $\mathrm{A}$, in which the recovery of swede dry matter was $219 \mathrm{~g} / \mathrm{kg}$ of that consumed, were selected to evaluate a number of representative methods of dietary fibre analysis. The selected methods were used to prepare fractions of both feed and digesta. For comparative purposes, analysis of each fraction was by the methods described here rather than those selected by the authors.

The extraction techniques of Theander \& Aman (1979b) and Chen \& Anderson (1981) both include fractionations of an alcohol-insoluble food residue into water soluble or insoluble components, after enzymic removal of any starch present with an amylase (EC 3.2.1.1 and 3.2.1.2) or amyloglucosidase (EC 3.2.1.3) preparation. These methods gave dietary fibre values (Table 5) of $243 \mathrm{~g} / \mathrm{kg}$ (Theander \& $\AA$ man, $1979 \mathrm{~b}$ ) and $225 \mathrm{~g} / \mathrm{kg}$ (Chen \& Anderson, 1981) diet compared with $219 \mathrm{~g} / \mathrm{kg}$ swede dry matter recovered in the digesta. Both methods overestimated soluble uronic acids and insoluble cellulose in the diet compared with the ileal digesta analysis while giving low recoveries of soluble phenolic material (Table 5). The chief quantitative difference between the prepar- 
Swede cell-wall digestion and dietary fibre

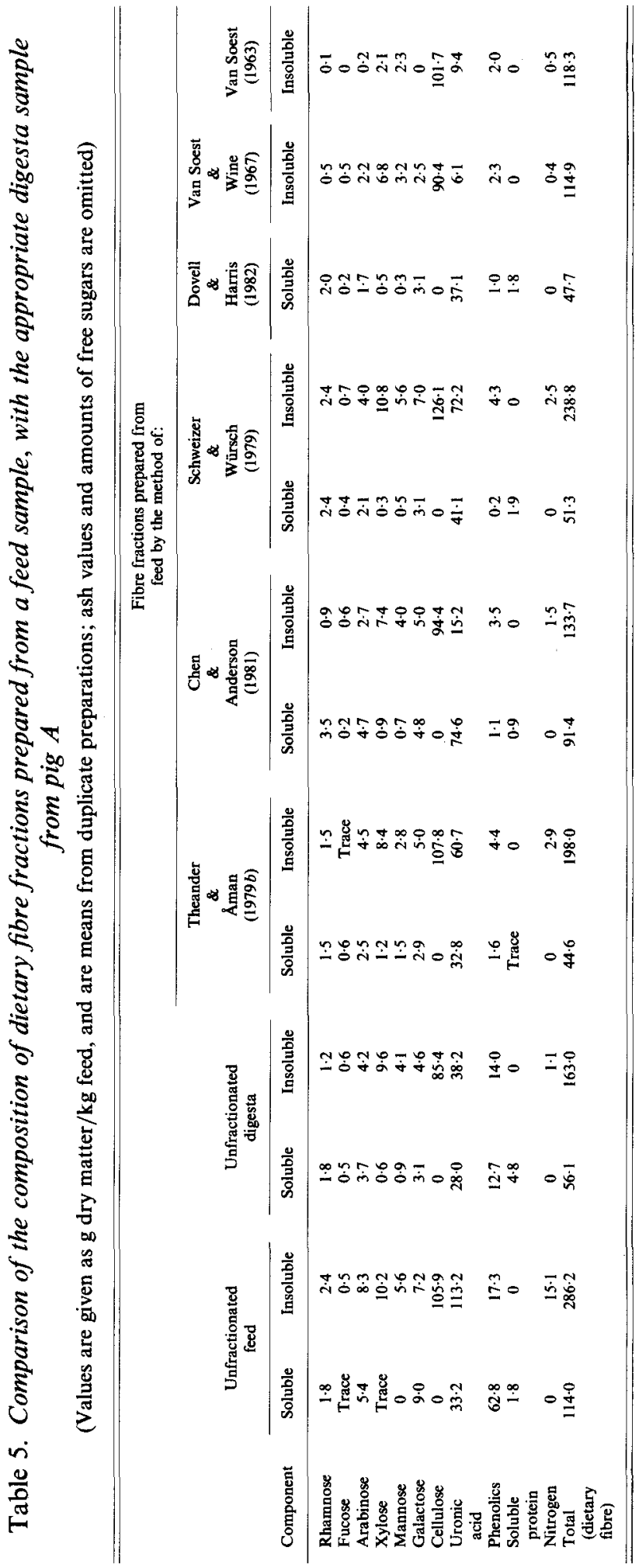


ations was in the recovery of uronide: insoluble uronide was overestimated by the method of Theander \& $\AA \operatorname{man}(1979 b)$ compared with the digesta sample, and underestimated by the method of Chen \& Anderson (1981).

Both these methods compared favourably with the in vitro enzymic digestion technique used by Schweizer \& Würsch (1979), which attempts to mimic the effects of passage of food through the small intestine on dietary fibre. This gave an estimate of $288 \mathrm{~g}$ dietary fibre $/ \mathrm{kg}$ (Table 5) and overestimated all the main fibre components, particularly insoluble uronic acid, galactose and mannose. Their value for insoluble fibre in the diet was therefore $46 \%$ higher than that recovered from the digesta. It is unclear why more cellulose was recovered from digesta than was present in the feed, but this was not due to retrograde starch.

The method of Dovell \& Harris (1982) produces a soluble fibre fraction extracted by ion-exchange resin (to remove soluble pectins) and an insoluble residue which is treated with enzyme preparations similar to those used by Schweizer \& Würsch (1979). However, incomplete separation of the resin from the insoluble fraction meant that only analysis of the soluble fraction could be achieved (Table 5). This method overestimated soluble uronide compared with recoveries from digesta, and underestimated soluble fucose, arabinose, xylose and mannose as the method did not allow for the solubilization of the hemicellulose found at the terminal ileum. The overall recovery of soluble fibre was only $84 \%$ of those components identified in the soluble digesta.

The detergent extraction methods developed by Van Soest and his co-workers (Van Soest, 1963; Van Soest \& Wine, 1967; Goering \& Van Soest, 1970) give an estimate of cellulose, hemicellulose and lignin by NDF extraction or cellulose and lignin by ADF extraction. The recovery of insoluble fibre was low compared with the insoluble feed residues found in the digesta, and there were substantial losses of uronic acid, hemicellulose and phenolic material.

\section{Comparative analysis of a digesta sample}

It is evident from the previous section that the composition of fibre in feed, as determined by the published methods of analysis, differed in a number of important respects from that of the corresponding digesta sample. These differences were a product of two factors, namely, the inability of any of the methods to take account of microbial or other digestive action in the small intestine, and shortcomings in the analytical methods themselves. To examine the second of these two factors further the preparatory techniques already described were also applied directly to the digesta sample from pig A referred to previously (Table 6). Some $540 \mathrm{~g} / \mathrm{kg}$ digesta was dietary fibre, while the rest comprised $220 \mathrm{~g}$ ash, $80 \mathrm{~g}$ VFA and $160 \mathrm{~g}$ unidentified components $/ \mathrm{kg}$. None of the methods recovered all the dietary fibre components. All gave low yields of soluble and insoluble neutral sugars and insoluble phenolics, and none adequately reflected soluble or insoluble uronide constituents. The extraction methods of Theander \& Åman $(1979 b)$ and Chen \& Anderson (1981) gave the most satisfactory quantitative recoveries of 387 and $415 \mathrm{~g} / \mathrm{kg}$ respectively and provided the best account of insoluble cell wall material.

\section{DISCUSSION}

A major criterion in evaluating non-ruminants as models for dietary fibre studies in humans is their ability, relative to that of man, to retain and digest plant fibre. Digestion of fibre in man occurs to a greater extent than in small mammals such as the rabbit or rat, but to a lesser extent than in the pig (Van Soest $e t$ al. 1983). Such overall comparisons do not, however, provide any indication of the importance of different sites of fermentation, much or all of which is assumed to occur in the hind-gut. The small intestine of pigs is also extensively and permanently colonized by micro-organisms. VFA have been identified in 


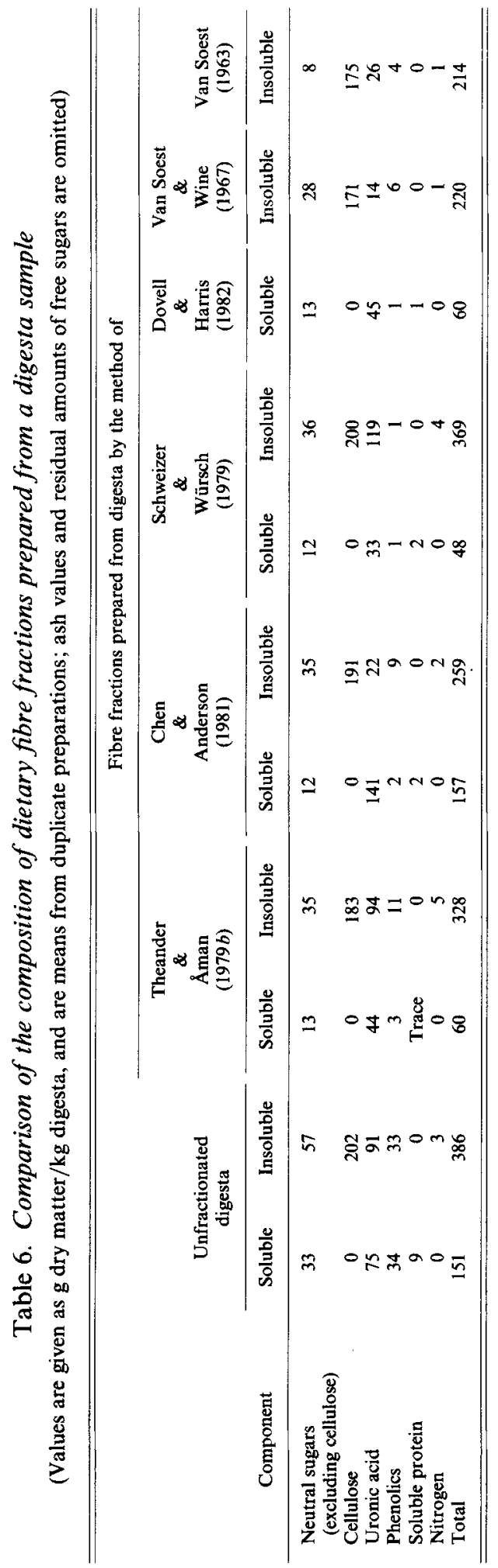


the stomach and small intestine of slaughtered pigs (Friend et al. 1963a; Argenzio \& Southworth, 1975; Clemens et al. 1975) and in digesta collected from duodenum, midjejunum and terminal ileum (Sambrook, 1979). The chief organic acids found were lactic and acetic acids, with lesser quantities of propionic and butyric acids, as found in the present investigation. Lactic acid, detected in substantial amounts in digesta from the terminal ileum (Table 4), was found as a minor component only of organic acids in the caecum and colon by Friend et al. $(1963 a, b)$. This makes it unlikely that the organic acids found represented contamination with material from the large intestine due to a disturbed flow of digesta caused by cannulation. However, VFA can be formed by the fermentation of any carbohydrate, and Mason \& Just (1976) have shown that where the diet contains more digestible or fermentable carbohydrate there will be relatively more fermentation in the stomach and less in the large intestine. The identification of VFA in the digesta is therefore indicative only of the presence of microbes anterior to the terminal ileum.

A loss of 'hemicellulose' (measured by the difference between cell wall content and ADF values) of up to $47 \%$ before the terminal ileum, was found by Keys \& DeBarthe (1974) who gave diets containing $300 \mathrm{~g}$ cell wall material $/ \mathrm{kg}$ diet to $82-90-\mathrm{kg}$ pigs fitted with $\mathrm{T}$-shaped cannulas. For one diet used these workers also recorded a $33 \%$ apparent digestion of cellulose anterior to the terminal ileum. Sambrook (1979) also reported a loss of ADF from the diet anterior to the duodenum and between the mid-jejunum and terminal ileum of $30-\mathrm{kg}$ pigs fitted with re-entrant cannulas. Although these results suggest that microbial fermentation of cell wall components can occur anterior to the terminal ileum, the authors of both studies expressed some doubt about the general significance of their findings and both suggested that the loss of cellulose in the small intestine may have been an artefact.

The results obtained in the present investigation point to a substantial loss of pectic polysaccharides, phenolic material and $(1 \rightarrow 4)$-linked glucan (cellulose) from swede residues recovered from the terminal ileum (Table 1). The calculation of the magnitude of these losses was dependent on the recovery of the dual markers used. It is well recognized that the use of $\mathrm{Cr}_{2} \mathrm{O}_{3}$, in particular, may give rise to biased results (Beever et al. 1978). However, recalculating the recoveries of water-insoluble components using cellulose itself as a marker for the insoluble phase (and assuming no loss) showed that xylose was recovered from digesta in amounts greater than that consumed. This strongly suggests that a loss of cellulose, of similar magnitude to that detected by the use of $\mathrm{Cr}_{2} \mathrm{O}_{3}$, had occurred.

Subsequent work with unmodified animals, in which the entire digestive tract was removed, sectioned and each section examined for microbial activity, has shown that both cellulolytic and pectinolytic bacteria are present in substantial numbers in swede-fed animals. In contrast, no cellulolytic organisms were isolated from bran-fed animals and numbers of pectinolytic bacteria were much reduced(P. Millard and A. Chesson, unpublished results).

Micro-organisms in the human ileum may be fewer in number and may be more transitory than is typical of the pig (Drasar \& Hill, 1974). Nonetheless, studies with ileostomy patients have shown significant losses of 'dietary fibre' components in the upper digestive tract. Analysis of the ileostomy contents of Swedish patients receiving bran or pectin showed maximum losses of approximately $20 \%$ of ingested bran cell walls and $30 \%$ of ingested pectin (Sandberg, 1982). In a similar study in New Zealand, Holloway et al. (1983) also detected a loss of $15-45 \%$ of ingested pectic substances in the small intestine. Although these values are lower than the 46-50\% loss of pectic substances found for the pig (Table 1), the patients examined were, in both cases, from industrial-type societies. Residents of non-industrial-type societies, whose diets generally are richer in carbohydrate and hence dietary fibre, have been shown to support an ileal flora in which the numbers of anaerobes 
approach that of the pig (Bhat et al. 1972). Thus the microbial modification of fibre anterior to the terminal ileum may be greater in these subjects.

The results from this and other studies with surgically modified pigs and those obtained with ileostomy patients indicate that, in the case of vegetable fibre at least, dietary fibre at the terminal ileum has already been hydrolysed to some extent. Although methods of fibre analysis have been developed which reflect the composition and structure of plant cell walls, they cannot predict modification of these structures in the small intestine and beyond (Table 5). Useful information from clinical trials or epidemiological studies may be obtained by correlation of dietary fibre intake (often calculated from information provided in food tables) with effects noted in small or large bowel to indicate the value or otherwise of a high-fibre diet. However, when considering the possible physiological role of fibre or fibre components in the diet, a more dynamic model of dietary fibre, in which the effects of gut micro-organisms are considered, may be more appropriate. In this case perhaps the only valid measure of dietary fibre would be the recovery and analysis of digesta from the site of interest. Clearly this approach poses considerable ethical and practical problems when applied directly to human digestion and points to the need for a suitable model, such as the pig digestive tract, as an alternative.

The authors would like to thank Dr R. M. Livingstone and Mr C. A. Simpson for the surgical preparation of the pigs and Ms Sandra Bain for her skilled assistance.

The results of the research, the contents of which are reported in the document, are the property of the Ministry of Agriculture, Fisheries and Food and are Crown Copyright.

\section{REFERENCES}

Argenzio, R. A. \& Southworth, M. (1975). American Journal of Physiology 228, 454-460.

Association of Official Agricultural Chemists (1965). Official Methods of Analysis. Washington DC: Association of Official Agricultural Chemists.

Bacon, J. S. D. \& Gordon, A. H. (1980). Journal of Agricultural Science, Cambridge 94, 361-367.

Beever, D. E., Kellaway, R. C., Thomson, D. J., MacRae, J. C., Evans, C. C. \& Wallace, A. S. (1978). Journal of Agricultural Science, Cambridge 90, 157-163.

Bhat, P., Shantatumari, S., Rajan, D., Mathan, V. I., Kapadia, C. R., Swamabi, C. \& Baker, S. J, (1972). Gastroenterology 62, 11-21.

Blakeney, A. B., Harris, P. J., Henry, R. J. \& Stone, B. A. (1983). Carbohydrate Research 113, $291-299$.

Burkitt, P. P. \& Trowell, H. C. (1975). Refined Carbohydrate Foods and Diseases. London: Academic Press.

Chen, W. L. \& Anderson, J. W. (1981). American Journal of Clinical Nutrition 34, 1077-1082.

Clemens, E. R., Stevens, C. E. \& Southworth, M. (1975). Journal of Nutrition 105, 759-768.

Conway, E. J. (1957). Microdiffusion Analysis and Volumetric Error. London: Crosby Lockwood.

Cummings, J. H. (1981). In Nutrition and Health: a Perspective, pp. 35-48 [M. R. Turner, editor]. London: MTP Press Ltd.

Dovell, C. J. \& Harris, N. D. (1982). Journal of the Science of Food and Agriculture 33, 185-193.

Drasar, B. S. \& Hill, M. J. (1974). Human Intestinal Flora. London: Academic Press.

Friend, D. W., Cunningham, H. M. \& Nicholson, J. W. G. (1963a). Canadian Journal of Animal Science 43, 174-181.

Friend, D. W., Cunningham, H. M. \& Nicholson, J. W. G. (1963b). Canadian Journal of Animal Science 43, 156-168.

Goering, H. K. \& Van Soest, P. J. (1970). Forage Fiber Analyses. US Department of Agriculture. Agricultural Handbook no. 379. Washington DC: US Department of Agriculture.

Hellendoorn, E. W., Nordohoff, M. G. \& Shagman, J. (1975). Journal of the Science of Food and Agriculture 26, 1461-1468.

Hesford, F. \& Buhrer, M. (1978). Clinica Chemica Acta 82, 225-228.

Holloway, W. D., Tasman-Jones, C. \& Maher, K. (1983). American Journal of Clinical Nutrition 37, $253-255$.

Keys, J. E. \& DeBarthe, J. V. (1974). Journal of Agricultural Science, Cambridge 39, 53-56.

Kintner, P. K. \& Van Baren, J. P. (1982). Journal of Food Science 47, 756-759, 764.

Livingstone, R. M., Baird, B. A., Atkinson, T. \& Crofts, R. M. J. (1980). Journal of Agricultural Science, Cambridge 94, 399-405. 
Lomax, J. A. \& Conchie, J. C. (1982). Journal of Chromatography 236, 385-394.

Lomax, J. A., Gordon, A. H. \& Chesson, A. (1983). Carbohydrate Research 122, 11-22.

Malawar, S. J. \& Powell, D. W. (1967). Gastroenterology 53, 250-256.

Mason, V. C. \& Just, A. (1976). Zeitschrift für Tierphysiologie, Tierenährung und Futtermittelkunde 36, $301-310$.

Morrison, I. M. (1972). Journal of the Science of Food and Agriculture 23, 455-463.

Read, S. M. \& Northcote, D. M. (1981). Analytical Biochemistry 116, 53-64.

Sambrook, I. E. (1979). British Journal of Nutrition 42, 279-287.

Sandberg, A.-S. (1982). Dietary Fibre - Determination and Physiological Effects. Göteborg, University of Göteborg, Sweden.

Schweizer, T. F. \& Würsch, P. (1979). Journal of the Science of Food and Agriculture 30, 613-619.

Selvendran, R. R., Ring, S. G. \& DuPont, M. S. (1979). Chemistry and Industry 225-230.

Southgate, D. A. T. (1976). In Fiber in Human Nutrition, pp. 73-107 [G. A. Spiller and R. J. Amen, editors]. New York and London: Plenum Press.

Spiller, G. A., Fassett-Cornelius, G. \& Briggs, G. M. (1976). American Journal of Clinical Nutrition 29, 934-935. Supelco Inc. (1975), Technical Bulletin 749D. Bellefonte: Supelco Inc.

Theander, O. \& Åman, P. (1979a). In Dietary Fibers: Chemistry and Nutrition, pp. 215-244 [G. E. Inglett and S. I. Falkehag, editors]. New York and London: Academic Press.

Theander, O. \& Aman, P. (1979b). Swedish Journal of Agricultural Research 9, 97-106.

Trowell, H., Southgate, D. A. T., Wolevar, T. M. S., Leeds, A. R., Gassull, M. A. \& Henkins, D. J. A. (1976). Lancet i, 967.

Updegraff, D. M. (1969). Analytical Biochemistry 32, 420-424.

Van Soest, P. J. (1963). Journal of the Association of Official Agricultural Chemists 46, 829-835.

Van Soest, P. J., Feraci, J. \& Foose, T. (1983). In Fibre in Human and Animal Nutrition, pp. 75-80 [G. Wallace and L. Bell, editors]. Wellington: Royal Society of New Zealand.

Van Soest, P. J. \& Wine, R. H. (1967). Journal of the Association of Official Analytical Chemists 50, 50-55.

Wenham, G. \& Wyburn, R. S. (1980). Journal of Agricultural Science 95, 539-546. 